\title{
Global surgery and the World Health Organization: indispensable partners to achieve triple billion goals
}

\author{
Ché L. Reddy, MBChB, MPH • Rolvix H. Patterson, BA · Luke Caddell, MS • \\ Adrian W. Gelb, MBChB, FRCPC · Desmond T. Jumbam, MSGH · Lauri Romanzi, MD, \\ MScPH $\cdot$ Isaac Wasserman, MPH $\cdot$ John G. Meara, MD, DMD, MBA
}

Received: 23 May 2019/Revised: 29 May 2019/Accepted: 29 May 2019/Published online: 25 June 2019

(C) Canadian Anesthesiologists' Society 2019

Every six years, the World Health Organization (WHO) presents a renewed vision and strategy to achieve its principal objective- "the attainment by all peoples of the highest possible level of health"-in its General Programme of Work (GPW). With its thirteenth GPW (GPW-13) under the leadership of Director-General Tedros Adhanom Ghebreyesus, the WHO aims to attain the "triple billion" target to ensure that an additional one billion people: 1) benefit from universal health coverage (UHC), 2) are protected from health emergencies, and 3) enjoy better health and wellbeing. ${ }^{1}$ The triple billion targets are aligned with and designed to support the attainment of

Ché L. Reddy and Rolvix H. Patterson are co-first authors.

John G. Meara is senior author.

C. L. Reddy, MBChB, MPH (ه) · D. T. Jumbam, MSGH ·

J. G. Meara, MD, DMD, MBA

Program in Global Surgery and Social Change, Department of Global Health and Social Medicine, Harvard Medical School, Boston, Massachusetts, USA

e-mail: chelen_reddy@hms.harvard.edu

Department of Plastic and Oral Surgery, Boston Children's Hospital, Boston, Massachusetts, USA

R. H. Patterson, BA

Program in Global Surgery and Social Change, Department of Global Health and Social Medicine, Harvard Medical School,

Boston, Massachusetts, USA

Tufts University School of Medicine, Boston, Massachusetts, USA

L. Caddell, MS

Program in Global Surgery and Social Change, Department of Global Health and Social Medicine, Harvard Medical School,

Boston, Massachusetts, USA

Miller School of Medicine, University of Miami, Miami, Florida, USA
Sustainable Development Goal 3 (SDG 3), the United Nations' global target to promote health and wellbeing - an essential strand of its eighteen-goal plan to eradicate poverty by 2030 .

In 2015, WHO member states declared surgical, obstetric, and anesthesia (SOA) care as both "critical" and "integral" components to achieve global health goals (UHC, primary healthcare [PHC] and emergency care) through the World Health Assembly Resolution 68.15 (WHA68.15). ${ }^{2}$ These shared goals will only be accomplished through collaboration. Utilizing the key strategic shifts in the GPW-13 to strengthen SOA systems will enable the global health community and WHO to attain the triple billion goals. This collaboration should encompass: 1) advocating for stronger SOA systems at a global level, 2) developing contextually

A. W. Gelb, MBChB, FRCPC

Department of Anesthesia \& Perioperative Care, University of California San Francisco, San Francisco, California, USA

World Federation of Societies of Anaesthesiologists, London, UK

L. Romanzi, MD, MScPH

New York City, New York, USA

I. Wasserman, MPH

Program in Global Surgery and Social Change, Department of Global Health and Social Medicine, Harvard Medical School, Boston, Massachusetts, USA

Icahn School of Medicine at Mount Sinai, New York City, New York, USA 


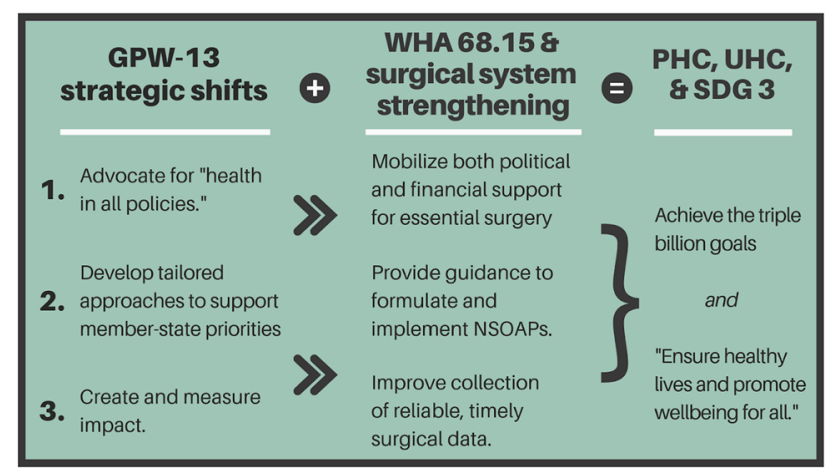

Figure A formula for advancing surgical system strengthening and World Health Assembly Resolution 68.15 through the World Health Organization's thirteenth General Programme of Work (GPW-13). This graphic depicts the three strategic shifts outlined in GPW-13 and ties them to specific avenues for surgical system strengthening to achieve overarching goals. GPW-13 = Thirteenth General Programme of Work; NSOAPs = National Surgical, Obstetric, and Anesthesia Plans; PHC = primary healthcare; SDG $3=$ Sustainable Development Goal 3; UHC = universal health coverage; WHA $68.18=$ World Health Assembly resolution 68.15

relevant policies to improve SOA care at a national level, and 3) creating stronger SOA data systems to measure impact at both national and global levels.

Access to surgery remains a major unmet global health imperative. ${ }^{3}$ The Lancet Commission on Global Surgery determined that approximately five billion people lack access to safe, affordable, and timely surgical, obstetric, and anesthesia care needed to address an estimated $30 \%$ of the global burden of disease. ${ }^{4}$ The WHO is uniquely positioned to facilitate and influence policy dialogue by using its global advocacy platform to emphasize the importance of high-quality SOA care. This will require consistent leadership and governance to mobilize broadbased political and financial support for SOA care.

Sustainable transformation - a key theme throughout the GPW-13-relies on the extent to which the interdependent priorities in global health are addressed through countryinspired approaches. In 2015, WHO member states declared the need for safe surgery and anesthesia by unanimously signing WHA 68.15. This paradigm shift was a bold statement as it established SOA care as an essential component of the major global health priority areas of PHC, UHC, and emergency care. As a result, SOA care has amassed the attention of national policymakers intent on strengthening health systems, thus catalyzing the development of National Surgical, Obstetric, and Anesthesia Plans (NSOAPs). ${ }^{5}$

In three years, five NSOAPs have been signed and launched, and over twenty countries have committed to initiating similar processes. ${ }^{5,6}$ The growing demand for NSOAPs by member states implicitly acknowledges that many health systems provide inadequate SOA care.
Without actively supporting the development of NSOAPs, the WHO and member states will fall short of their shared health goals. Moreover, the provision of safe surgery is essential to curb the rising tide of iatrogenic harm occurring because of poor-quality SOA delivery. ${ }^{7}$ A multi-sectoral approach is needed to address this gap in health systems. NSOAPs provide this approach through a country-led, integrated policy model to strengthen global health systems.

The importance of measuring impact, the third strategic shift in the GPW-13, is underscored by the substantial limitations present in global SOA data. Low- and middleincome country SOA systems exist in a data-vacuum, where the lack of surgical indicators restrict the ability to identify the most pressing needs, plan appropriate service delivery, and evaluate ongoing interventions. ${ }^{4}$ Member states require support from all levels of global health governance to fill this lacuna. Well-aligned partnerships like that of the WHO and the Institute for Health Metrics and Evaluation ${ }^{8}$ are extremely valuable in bolstering data systems at the global level. Nevertheless, increased collaboration between the WHO and nation states is needed to strengthen and institutionalize data systems at the national level, helping to inform context-specific NSOAPs and amplify progress towards the triple billion goals.

The GPW-13 represents an institutional shift in the WHO, indicating a readiness to adapt to contemporary global health demands in pursuit of the sustainable development goals (SDGs) and beyond. Although SOA care is one of many global health imperatives, it provides a distinct opportunity within the context of GPW-13 to achieve the triple billion goals through WHA 68.15 and attain the SDGs. This renewed vision and strategy comes at a timely point in the global movement to provide safe and affordable SOA care for all. ${ }^{3}$

Conflicts of interest None declared.

Editorial responsibility This submission was handled by Dr. Hilary P. Grocott, Editor-in-Chief, Canadian Journal of Anesthesia.

\section{References}

1. World Health Organization. Thirteenth General Programme of Work 2019-2023. Promote Health - Keep the World Safe - Serve the Vulnerable. Available from URL: https://apps.who.int/iris/ bitstream/handle/10665/324775/WHO-PRP-18.1-eng.pdf (accessed May 2019).

2. 68th World Health Assembly. WHA 68.15 Strengthening emergency and essential surgical care and anaesthesia as a component of universal health coverage. Provisional agenda item 17.1 - 2015 (May 26). Available from URL: www.apps.who.int/ 
gb/ebwha/pdf_files/WHA68/A68_R15-en.pdf (accessed May 2019).

3. Global Health Now. A Surprise Beginning for \#WHA72. Available from URL: https://www.globalhealthnow.org/2019-05/ surprise-beginning-wha72 (accessed May 2019).

4. Meara JG, Leather AJM, Hagander L, et al. Global Surgery 2030: evidence and solutions for achieving health, welfare, and economic development. Lancet 2015; 386: 569-624.

5. Albutt K, Sonderman K, Citron I, et al. Healthcare leaders develop strategies for expanding national surgical, obstetric, and anaesthesia plans in WHO AFRO and EMRO regions. World J Surg 2018; 43: 360-7.
6. Program in Global Surgery and Social Change. 2019 Dubai NSOAP Planning Con. Available from URL: https://www.pgssc. org/2019-national-surgical-planning (accessed May 2019).

7. Kruk ME, Gage AD, Arsenault $C$, et al. High-quality health systems in the Sustainable Development Goals era: time for a revolution. Lancet Glob Health 2018; 6: e1196-252.

8. Horton R. Offline: WHO powers up in 2019. Lancet 2019; 393: 14.

Publisher's Note Springer Nature remains neutral with regard to jurisdictional claims in published maps and institutional affiliations. 